\title{
La presencia del "Sí mismo" en Escrito a ciegas de Martín Adán
}

\author{
Marcos Mondoñedo Murillo \\ Universidad Nacional Mayor de San Marcos \\ mindoniense@gmail.com
}

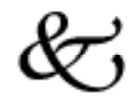

\section{Resumen}

Este trabajo pretende analizar los modos de manifestación de la presencia del "sí mismo" para el hablante lírico de Escrito a ciegas de Martín Adán. Se trata de una reflexión que asume, en principio, una perspectiva hegeliana respecto de la "voz". Para Hegel, la voz humana es la manifestación de lo viviente en el plano de la experiencia fenoménica para el propio ser humano. Postulamos que dicha "voz" y su actualización lírica en el poema permite un acceso al ser del hablante lírico al modo de una experiencia con la vitalidad de un yo que habita en el poema Escrito $a$ ciegas. Dicha vitalidad no radica en ninguna materialidad efímera sino en la configuración discursiva de un ser como mediador evanescente entre los lectores del poema y la experiencia del sí mismo.

Palabras claves: Escrito a ciegas, Martín Adán, singularidad, vitalidad, voz.

\begin{abstract}
This work try to analyze the modes of manifestation of the presence of "self" to the lyrical speaker in Escrito a ciegas by Martín Adan. This is a reflection that assumes, in principle, a hegelian perspective on the "voice." For Hegel, the human voice is the manifestation of the living at the level of phenomenic experience for the man himself. We postulate that the "voice" and update the lyric poem allows access to be the lyric speaker mode to experience the vitality of a self that inhabits the poem Escrito a ciegas.This vitality is not in any ephemeral materiality but in the discursive configuration of a being as vanishing mediator between readers of the poem and the experience itself.
\end{abstract}

Keywords: Escrito a ciegas, Martín Adán, Singularity, Vitality, Voice. 
Por todos es conocida la anécdota que gira en torno de la aparición de Escrito a ciegas en 1961. Este texto sería una respuesta poética de Martín Adán a un pedido que, por carta, le dirigiera la periodista argentina Cecilia Paschero. Se trataba de que el poeta escribiera un texto autobiográfico y, en vez de hacerlo, le envió este famoso poema. Desde un punto de vista, podríamos pensar que el texto en cuestión es una respuesta evasiva, que el poeta no entregó lo que se le demandaba. Y en tal sentido podrían entenderse los primeros versos del poema:

¿Quieres tú saber de mi vida?

Yo sólo sé de mi paso,

De mi peso,

De mi tristeza y de mi zapato.

Pero, ya que Martín Adán es principal o exclusivamente un poeta, entregar un poema incluso podría ser un exceso de entrega, un sobrepasarse a la demanda. Con este poema, más que hablar de su vida, habría construido un texto como un lugar para vivir. Desde este segundo punto de vista, podríamos incluso decir que el poeta estaría allí en Escrito a ciegas, dispuesto al encuentro de quienes quisieran conocerlo, viviendo en los versos del poema.

Esto, se me dirá, pasa siempre en la literatura y, para demostrarlo, quizás quisieran repetirme aquella idea de Emerson que a Borges le gustaba citar, la de la biblioteca como un "gabinete mágico", dentro del cual se encuentran los libros como espíritus encantados, a la espera del lector para revivir. No obstante, dada la situación y el modo en la que aparece este poema, podríamos decir que Martín Adán está en él de una manera específica y singular.

¿Cuál es esta manera? Recordemos que en el poema no se tematiza la historia individual; no se trata, pues, de datos que podrían haber sido la comidilla de cierto mundo que parasitaba -y aún parasita- al lado del quehacer literario: si comía butifarras en un viejo bar del centro de Lima, si tuvo una íntima relación con determinado poeta angloparlante, si fue sometido a algún tratamiento de shock por un afamado psiquiatra limeño y circunstancias por el estilo. Quizás esto fue lo que le pidieron, pero el poeta se excedió. Al responder con la famosa sentencia:

Si quieres saber de mi vida,

Vete a mirar al Mar.

Adán trató con generosidad de ubicar el huidizo ser, su ser en el poema; intentó aunque no lo parezca, inscribirlo o incluso hacerlo habitar en el Escrito a ciegas y de este modo vivir entre nosotros para siempre. 
Pero, ¿cómo se logra habitar en el poema y vivir en él más allá del cuerpo mortal? Lo que propongo es que lo que la tecnología imagina y promete desde hace algunas décadas fue logrado por Martín Adán quien, entre otros poetas, forma parte de un grupo selecto de poseedores de la clave, del secreto... que no es sino un secreto poético.

\section{2}

Se trata ni más ni menos que de aquella clave poética que, a pesar de serlo, se la debemos a un filósofo, Heidegger. Según uno de sus razonamientos, el ser del hombre es un ser de lenguaje o, dicho de otro modo, la palabra, es decir, la actualización de las posibilidades del código linguístico, es la casa en donde habita su ser. Dentro de este marco, la poesía es una actividad privilegiada para acceder al elusivo advenimiento del ser del hombre en la palabra. Pero nosotros queremos remontarnos un poco más atrás en la filosofía. Ya que uno de los antecedentes de este modo de hacer habitar al ser en el lenguaje se encuentra en una diferencia sutil que aquí queremos desarrollar, aunque sea brevemente, porque ella nos permitirá acceder a nuestro tema principal: la voz como soporte poético del yo mismo.

Se trata de una diferencia que Hegel establece entre la subjetividad y la conciencia. Esta, en tanto que tal, es conciencia de objetos; siempre ubicada en una especie de actitud de entrega hacia el mundo de la experiencia, siempre singular y sensorial. De este modo, la conciencia solo conoce el hecho particular experimentado y, para acceder a lo universal, requiere de la representación, que no es sino un modo de experiencia indirecta que el lenguaje le proporciona.

Pero la subjetividad es otra cosa. Ella está inscrita en una muy precisa experiencia, la del ser yo mismo como ser viviente. Dentro de nuestros propósitos actuales, nos interesa destacar que, para Hegel, la subjetividad se diferencia de la conciencia porque es una experiencia que tiene el yo de ser un yo vivo fundamentalmente a través de la voz. La propia voz, que no está dada meramente a la conciencia, con su cara sensible siempre puesta hacia el exterior; pero que tampoco es, exclusivamente, una sensación vital, incomunicable y ubicada en el interior. Al ser una exteriorización que, sin embargo, no se constituye en la realidad con ninguna consistencia fija, la voz es -como sostiene Josef Simon"la condición de posibilidad de que se experimente el ser uno mismo. Si el organismo es la condición de posibilidad de experimentar la singularidad o la objetividad del yo mismo, de su ser, no obstante su esencia como yo mismo o como vitalidad solo es experimentable a través de la voz" (Simon, 1982: 73).

En tal sentido la voz es una especie de puente o de intersección entre el mundo de los objetos y el mundo de la interioridad y de la experiencia de 
ser un sí-mismo viviente. Esta voz es, también, siempre singular a la par que universal porque no solo concilia el interior y el exterior del ser vivo, sino que conecta la específica vitalidad de una voz con la lógica de la representación en general. Esto es así porque la voz de un individuo que toma la palabra y dice es una voz material y específica de alguien y de nadie más. Sin embargo, esa voz se asume como soporte material de un discurso que, para serlo, necesita inscribirse dentro de las coordenadas de lo convencional, las de una lengua que permita la comunicabilidad universal. De este modo, la voz es singular por un lado y al mismo tiempo es universal.

\section{3}

Por su puesto que de la voz singular y concreta de Martín Adán no quedan sino huellas: sus libretas negras emborronadas, sus libros editados por su gran amigo Mejía Baca, sus grabaciones de poemas recitados. Pero la de Escrito a ciegas, es una escritura de tal naturaleza que se halla muy cerca de la oralidad. Como sostiene Hildebrando Pérez, este libro sería una "confesión en alta voz" que "se instala en el plano oral de la lengua", en "el lenguaje de la calle, lejos ya de la academia" (Pérez, 2006: s/n). Estas afirmaciones podrían resultar extrañas si nos remitimos al solemne tema de este poema: el ser del yo mismo. En todo caso, nosotros pensamos que esa oralidad que exhala el poema tiene su causa radical en la instancia de la voz, aquella que es "la condición de la posibilidad de la experiencia de la esencia enteramente general del yo mismo en el ámbito objetivo" (Simon, 1982: 76). Es decir que, con la voz, resulta posible experimentar el yo mismo como un fenómeno comunicable, como un mensaje que pueda transmitirse entre el yo mismo de Adán y el otro, en este caso, cada uno de nosotros, los lectores de Escrito a ciegas. Pero lo importante es que no se trata aquí del soporte material de la voz que emanaba del cuerpo vivo de Martín Adán, sino de la "esencia enteramente general" de su voz en tanto que vivo: esa doble condición de singular y universal, de interior y exterior. De este modo, la oralidad del poema se inscribe a partir de su presencia como voz, es decir como aquello que captura lo más fundamental de la experiencia del yo en tanto vivo.

Ahora bien, podrían decirme que esto no es nada específico, que dicha voz es la voz de todo poema escrito por Adán y por cualquier otro poeta de cualquier otra lengua. ¿Qué es aquello que hace la especificidad de nuestro poema? La respuesta es: la marca en sus versos de un cierto saber sobre el estatuto de la voz como materia y medio para la pervivencia más allá de la particularidad orgánica. ¿Y qué demuestra esta consciencia inscrita en sus versos? Esta inscripción, esta marca de subjetividad resulta observable en la organización de sus versos dentro 
de una estructura dialógica. Lo específico aquí es que existe en la voz del hablante lírico una conciencia del carácter elusivo del ser y, por lo tanto, existe también el recurso de privilegiar, no el mensaje comunicado, sino el propio acto de comunicar. Este recurso le permite capturar la fugacidad del ser del sujeto, tan fugaz como su voz, y fijarla en el lazo que implica una relación de comunicación. Varios son los pasajes que permiten esta observación, por ejemplo:

Cuando lo sepas todo...

Cuando sepas no preguntar...

Sino roerte la uña de mortal,

Entonces te diré mi vida,

Que no es más que una palabra más...

En estos versos, la conjugación del verbo saber en el presente del subjuntivo está en segunda persona. ("Cuando lo sepas todo..." por ejemplo). Esto claramente inscribe los versos en el marco de un diálogo con su destinataria figural (Cecilia Paschero) y con el destinatario implícito de todo discurso dialógico escrito. Lo interesante de este pasaje es que pone énfasis en las condiciones que el destinatario requiere para llegar a serlo de un momento de conversación futuro. ("Entonces te diré de mi vida,"). Sin embargo, a continuación, la voz del yo lírico expone la respuesta que supuestamente será dada en ese futuro indeterminado; como si no pudiese esperar, dice de su vida, "Que no es más que una palabra más...”. De este modo, diluye la importancia del tema de conversación y, al mismo tiempo, pone de relieve el acto mismo de conversar. De este modo, el tema de conversación, su vida, queda fijado al futuro lazo comunicativo para habitar en él como una posibilidad abierta.

Interesante es también observar que la versión impresa de este verso en la primera edición dice hacia el final, como hemos citado, “...una palabra más...”; sin embargo, en la página 6 de la libreta negra D367, este mismo verso dice “...una palabra de más...”. En el primer caso, aquella palabra que está en el lugar de su "vida" se añade a la conversación; de este modo, el tema de la vida del poeta y la situación de conversación con el poeta se relacionan en un lazo fluido de continuidad que los confunde. En el segundo, si la palabra que es su vida es una palabra de más, de lo que se trata con ella es de un resto, de una excrescencia inútil. Esto debió ser eliminado porque, después de todo, si bien el conversar es lo que aquí se destaca -y en este caso de un modo violento-, lo conversado no es algo que pueda obviarse en toda conversación: para conversar hay que tener un tema, incluso si esto no es lo importante de la conversación. Otro pasaje semejante en su estructura dialógica es el siguiente:

iCuando no seas nada más que ser,

Si llegas a la edad de la agonía!... 
iCuando sepas, verdaderamente,

Que es ayuntamiento de muerte y vida!...

iEntonces te diré quién soy,

Seguro, sí, que ya sin voz, Amiga!

Una vez más, aquí se pone énfasis en las condiciones del destinatario para una futura conversación. En estas condiciones se destaca una relación entre la vejez ("la edad de la agonía”), momento en el que el vínculo existencialista entre la muerte y la vida se hace evidente, y el ser. Es como si la condición de posibilidad de aquella futura e indeterminada conversación fuese el levantamiento de las vanidades de la vida y de su dimensión meramente sensible y, además, una aproximación a la conciencia del sentido de la vida como inserta sobre el horizonte de la muerte. Es quizás por eso que, en este caso, el poeta ya no declara que el tema de conversación será "mi vida", que podría confundirse con lo anecdótico y, por lo tanto, con lo trivial; sino que ahora, muchos versos después, de lo que se tratará es del ser: "iEntonces te diré quién soy,", dice, pero añade: "Seguro, sí, que ya sin voz, Amiga!".

\section{4}

¿Cómo que "ya sin voz"? ¿No es la voz la que sosteníamos como lo fundamental para la observación de la subjetividad? ¿No era la voz lo que permitía convertir la subjetividad en objeto de la experiencia dialógica, tanto para el sí mismo como para el otro, el lector? Para responder a estas interrogantes debemos recordar que, según Hegel, la voz no es el fundamento del ser sino el medio para acceder a la experiencia del ser un "yo vivo" como algo objetivo. En consecuencia, la voz debe desaparecer en su opacidad cuando adviene dicha experiencia. Esto, además, permitiría explicar la relación de coherencia entre dos aparentes contradictorios: la solemne dimensión ontológica del poema y su coloquialismo de la calle.

Dicho en otros términos, lo esencial de la voz es sostener la posibilidad de experimentar la vitalidad de un yo, tanto para el sí mismo del poema como para nosotros sus lectores, $y$, al hacerlo, desaparecer. La voz en este sentido, es un mediador evanescente. En consecuencia, cuando el poeta declara "iEntonces te diré quién soy, /Seguro, sí, que ya sin voz, Amiga!" estaría definiendo a la voz como un medio fugaz para el advenimiento de la experiencia del yo vivo de Adán que fue, precisamente, lo reclamado por la destinataria figural, Paschero.

Sin embargo, podemos esbozar otra respuesta: cuando se dice "...ya sin voz..." se lo dice con lo esencial de la voz. Dicho en términos más precisos “... ya sin voz..." es un enunciado que pone en evidencia una precisa enunciación. Y es que lo fundamental de la voz que delata el ser vivo del yo mismo, radica, no 
en lo que dice, sino en su decir; no en los enunciados -que en este caso tendrían de tema la vida de un tal Rafael de la Fuente Benavides, según el pedido de Paschero- sino la enunciación de Martín Adán. ¿Y cuál es esa enunciación? Pues, como es obvio decir ahora, se trata de aquella que se delata como el fundamento de la vida de un hombre singular: esa causa vacía, ese no saber radical que está en una dimensión ontológica. Esto en pocas palabras se dice mejor con un solo verso del poema: “¿Quién soy? Soy mi qué”.

Dicho sin la fabulosa síntesis de Adán, esto significa que en aquel punto de la vida, cuando un hombre, que se arroga el "yo" universal para presentarse a sí mismo, se detiene y se interroga por aquello que está detrás de lo que, en sus palabras, es lo "Inefable e innumerable" de las apariencias que se adquieren y se dejan como representaciones en una vida; en aquel punto, cuando queremos llenar el "soy" con algún volumen, con alguna presencia importante y representativa de toda representación, no podemos sino, para ser sinceros, ubicar allí no otra cosa sino la pregunta misma: "Soy mi qué". Ninguna presencia que haga las veces de respuesta alcanzará la dignidad del vacío estructural que solo podría ser representado por la pregunta misma. "Soy mi qué".

Para confirmar esta estrategia de llenado de la apertura con la propia apertura, podríamos citar otros versos como los siguientes:

Yo buscaba otro ser,

Y ése ha sido mi buscarme

Yo no quería ni quiero ya ser yo,

Sino otro que se salvara o que se salve,

No el del Instinto, que se pierde,

$\mathrm{Ni}$ el del Entendimiento, que se retrae.

En los dos primeros versos, el buscar algo, el "otro ser", se colma con la propia búsqueda del sí mismo ("mi buscarme"). Esto se corrobora con el vaciamiento que se produce a continuación: el otro aquel, que debería llenar este lugar del ser y salvarse, no es ni del Instinto ni del Entendimiento. Estas negaciones no son luego llenadas con ninguna presencia. El ser así queda abierto, en sí mismo.

\section{5}

Esta pura apertura como ser es un hallazgo que contrasta con otros momentos del poema en los cuales todavía no se había producido. El poema, en tal sentido, toma la forma, en algunos pasajes, del relato de un antes del hallazgo del ser como un puro abierto. Existe un pasaje en la página 30 de la libreta negra D367 que fue omitido en la primera edición y en todas las demás ediciones impresas: 
Y escribí libros para persuadirme

A que yo era alguien,

Uno según mi gana

O según mi nadie.

Quizás por su carácter narrativo -que desentonaría con el resto del poema-, este fragmento fue suprimido de la publicación; sin embargo, para nuestro propósito actual, nos sirve para contrastarlo con los anteriores citados en la medida en que la voz declara aquí que no fue inmediato, como es verosímil suponer, el encuentro del ser como un vacío radical. Antes de este hallazgo, propio de "la edad de la agonía", lo que se ubicó en aquel lugar fueron presencias que, a modo de libros, le daban consistencia y volumen al ser. Dicho de otro modo, hubo un tiempo en que la pregunta “¿Quién soy?” se respondía con "el que escribió estos libros".

Dentro de este orden de cosas, resulta posible interpretar que para este "sí mismo" vivo en los versos de Escrito a ciegas la poesía es el equivalente de esas presencias que ocupan el lugar vacío del ser. En un famoso pasaje, que podría considerarse una poética de Adán, es decir, una reflexión sobre el propio quehacer poético, puede leerse:

La Poesía es, Amiga,

Inagotable, incorregible, ínsita.

Es el río infinito

Todo de sangre,

Todo de meandro, todo de ruina y arrastre de vivido...

En tal sentido, la poesía es para Adán el resultado de un conjunto de objetos sucesivos, vitales e incesantemente buscados como los que ocuparían el definitivo lugar del ser. Todos ellos, sin embargo, adquieren el cariz de la "ruina" de aquello que, como rémora, se transforma en el "arrastre de lo vivido". La Poesía es, entonces, un objeto resto, producto sedimentario del incesante buscar en la vida la Presencia perfecta. Esta búsqueda solo traerá como correlato el reconocimiento, no de su inutilidad porque solo a través de ella resulta posible algo de valor, sino de la certeza de que no hay La Presencia o que ella es constitutivamente perdida.

\section{6}

En síntesis, el carácter de la voz tal y como nos la muestra la filosofía hegeliana, en el cruce de dos tensiones -aquella entre lo singular y lo universal, por un lado y por el otro la que obra entre lo subjetivo incomunicable y lo objetivo experimentable-, esta voz nos ha permitido orientarnos en el esclarecimiento 
del modo del "sí mismo" como experiencia de lo vivo de un yo que habita en el poema Escrito a ciegas. Si su especificidad en tanto que tal no radica en ninguna materialidad efímera sino en su ser tensionado y mediador evanescente de la experiencia del sí mismo como vivo, entonces podemos afirmar que Martín Adán como emisor de esta voz "vive" en el poema.

Esto, que podría ser una generalidad aplicable a todo texto, cobra un relieve especial en el poema de Adán debido a una reconocible consciencia poética respecto de este modo de vida más allá de lo meramente orgánico. Para este efecto, inscrito en un diálogo que trasciende la coyuntura anecdótica, el poema devela las presencias sucesivas y vitales como productoras de un objeto residual a través del cual el devenir de lo vivo se avizora radicado en un ser que se llena con la misma pregunta por el ser. Repitamos, para finalizar, esta síntesis inagotable: “¿Quién soy? Soy mi qué”.

\section{Referencias bibliográficas}

ADÁN, Martín (2010) Escrito a ciegas. (“Manuscrito” y “Edición de 1961”) http://www. pucp.edu.pe/biblioteca/martin_adan/hoj_esc.php. Consultado el 16/03/2010 05:29 p.m.

ADÁN, Martín (2006). Escrito a ciegas (Carta a Cecilia Paschero). Lima: Sur Librería Anticuaria.

KINSELLA, John (1989). Lo trágico y su consuelo: estudio de la obra de Martín Adán. Lima: Mosca Azul.

PÉREZ, Hildebrando (2006) "Escrito a ciegas: un resplandor perpetuo". En ADÁN, Martín. Escrito a ciegas (Carta a Cecilia Paschero). Lima: Sur Librería Anticuaria.

SIMON, Josef (1982). El problema del lenguaje en Hegel. Madrid: Taurus. 